\title{
Epidemiology of sepsis in intensive care units in Turkey: a multicenter, point-prevalence study
}

Nur Baykara ${ }^{1 *}$, Halis Akalın², Mustafa Kemal Arslantaş ${ }^{3}$, Volkan Hancı ${ }^{4}$ Çiğdem Çağlayann ${ }^{5}$, Ferda Kahveci ${ }^{6}$, Kubilay Demirağ ${ }^{7}$, Canan Baydemir ${ }^{8}$, Necmettin Ünal ${ }^{9}$ and Sepsis Study Group

\begin{abstract}
Background: The prevalence and mortality of sepsis are largely unknown in Turkey, a country with high antibiotic resistance. A national, multicenter, point-prevalence study was conducted to determine the prevalence, causative microorganisms, and outcome of sepsis in intensive care units (ICUs) in Turkey.

Methods: A total of 132 ICUs from 94 hospitals participated. All patients (aged > 18 years) present at the participating ICUs or admitted for any duration within a 24-h period (08:00 on January 27, 2016 to 08:00 on January 28, 2016) were included. The presence of systemic inflammatory response syndrome (SIRS), severe sepsis, and septic shock were assessed and documented based on the consensus criteria of the American College of Chest Physicians and Society of Critical Care Medicine (SEPSIS-I) in infected patients. Patients with septic shock were also assessed using the SEPSIS-III definitions. Data regarding demographics, illness severity, comorbidities, microbiology, therapies, length of stay, and outcomes (dead/alive during 30 days) were recorded.

Results: Of the 1499 patients included in the analysis, 237 (15.8\%) had infection without SIRS, 163 (10.8\%) had infection with SIRS, 260 (17.3\%) had severe sepsis without shock, and 203 (13.5\%) had septic shock. The mortality rates were higher in patients with severe sepsis (55.7\%) and septic shock (70.4\%) than those with infection alone (24.8\%) and infection + SIRS (31.2\%) ( $p<0.001)$. According to SEPSIS-III, 104 (6.9\%) patients had septic shock (mortality rate, 75.9\%). The respiratory system (71.6\%) was the most common site of infection, and Acinetobacter spp. (33.7\%) were the most common isolated pathogen. Approximately, 74.9\%, 39.1\%, and 26.5\% of Acinetobacter, Klebsiella, and Pseudomonas spp. isolates, respectively, were carbapenem-resistant, which was not associated with a higher mortality risk. Age, acute physiology and chronic health evaluation II score at ICU admission, sequential organ failure assessment score on study day, solid organ malignancy, presence of severe sepsis or shock, Candida spp. infection, renal replacement treatment, and a nurse-to-patient ratio of 1:4 (compared with a nurse-to-patient ratio of 1:2) were independent predictors of mortality in infected patients.
\end{abstract}

Conclusions: A high prevalence of sepsis and an unacceptably high mortality rate were observed in Turkish ICUs. Although the prevalence of carbapenem resistance was high in Turkish ICUs, it was not associated with a higher risk for mortality.

Trial registration: ClinicalTrials.gov ID NCT03249246. Date: August 15, 2017. Retrospectively registered.

Keywords: Intensive care, Sepsis, Carbapenem resistance, Point prevalence, Turkey

\footnotetext{
* Correspondence: Nur.Baykara@yahoo.com

${ }^{1}$ Department of Anesthesiology, Division of Critical Care, School of Medicine,

Kocaeli University, Kocaeli, Turkey

Full list of author information is available at the end of the article
} International License (http://creativecommons.org/licenses/by/4.0/), which permits unrestricted use, distribution, and reproduction in any medium, provided you give appropriate credit to the original author(s) and the source, provide a link to the Creative Commons license, and indicate if changes were made. The Creative Commons Public Domain Dedication waiver (http://creativecommons.org/publicdomain/zero/1.0/) applies to the data made available in this article, unless otherwise stated. 


\section{Background}

Sepsis is a global healthcare problem affecting millions of individuals [1-6]. An increase in the incidence of sepsis in developed countries has been shown in previous studies [1-3]. The incidence rate of sepsis was found to be 535 cases per 100,000 person-years, which is expected to increase in the United States (US) [7]. In a recent metaanalysis of 27 studies from 7 high-income countries, it was estimated that 31.5 million sepsis and 19.4 million severe sepsis cases occur annually worldwide [1]. This trend will likely continue due to the aging population with more chronic illnesses in developed countries, and the increased use of invasive procedures, immunosuppressive therapies, chemotherapies, and transplantations.

Although the sepsis mortality rate has declined in the last two decades due to advances in supportive care, as shown by recent reports from Western countries, the mortality rate is still unacceptably high and survival is frequently associated with long-term morbidity [8-11]. The mortality rate of sepsis (defined by ICD-9-CM) decreased between 1979 and 2000 in the US [10]. Similarly, the hospital mortality of severe sepsis decreased from $35.0 \%$ to $18.4 \%$ between 2000 and 2012 in Australia and New Zealand [11]. The mortality rate of sepsis might be different among countries and continents due to differences in the provision of intensive care facilities and treatments. According to two multicenter investigations, the hospital mortality rate of severe sepsis was still high $(48.7 \%$ and $33.5 \%)$ in China, which is the fastest-growing country of the world and constitutes a fifth of the world population [12,13]. The hospital mortality rate of severe sepsis was also found to be high (44.5\%) in Asia according to a study performed in 150 intensive care units (ICUs) from 16 countries in 2011 [14].

Currently, there are a limited number of large epidemiologic investigations regarding sepsis in middle- and low-income countries, where almost two-thirds of the world's population lives. The prevalence and mortality rate of sepsis in Turkey is largely unknown. Turkey is a middle-income country and is among the countries with a high level of antibiotic resistance [15]. It is unclear whether antibiotic resistance alone increases the mortality rate. In previous studies, it has been reported that infections caused by antibiotic-resistant bacteria were associated with a higher mortality ratio, longer ICU stays, and hospitalization costs [16, 17]. However, some other researchers claimed that drug resistance status alone was not a significant predictor of mortality if all patients received the appropriate initial antibiotic treatment $[18,19]$.

This national, multicenter, point prevalence study was conducted by the Turkish Society of Intensive Care Medicine, Sepsis Study Group to determine the prevalence, causative microorganisms, and mortality rate of sepsis in Turkish ICUs.

\section{Methods}

Study design, setting, and assembly of cohort

A nationwide, 1-day, point prevalence study was conducted on January 27, 2016. The study was announced on the Turkish Society of Intensive Care Medicine website, which included the study protocol, and the ICU directors (excluding cardiovascular surgery, coronary, and pediatric ICUs) were invited to participate in the study. The other method for recruiting the participating institutions included e-mail invitation to members of the Turkish Society of Intensive Care Medicine.

A total of 132 ICUs from 94 hospitals in Turkey agreed to participate in the study. The Kocaeli University Ethics Committee and Review Board served as the central ethics committee and approved the study for all participating centers (KOÜKAEK 2016/2). A copy of the ethics approval was sent to the study researchers before study commencement. Informed consent was obtained from all participants or their legally acceptable representatives.

All patients ( $>18$ years old) who were present at the participating ICUs or were admitted for any length of time during a 24-h period between 08:00 on January 27, 2016 and 08:00 on January 28, 2016 were included in the study.

\section{Data collection: demographic variables and comorbidities} The demographic information, date of ICU admission, admission source, primary diagnosis, comorbidities, acute physiology and chronic health evaluation (APA$\mathrm{CHE}$ II) score at admission, and sequential organ failure assessment (SOFA) score on study day were recorded for all patients. The presence of the following comorbid conditions was noted: solid organ malignancy, insulindependent diabetes mellitus, cerebrovascular accident, New York Heart Association functional class III-IV heart failure, chronic obstructive, restrictive, or vascular pulmonary disease, chronic liver disease, chronic renal failure (patients who are undergoing dialysis or a baseline serum creatinine $\geq 2 \mathrm{mg} \cdot \mathrm{dL}^{-1}$ ), and immunosuppression [neutropenia $\left(<500 \mathrm{~mm}^{-3}\right)$, hematologic malignancy, splenectomy, human immunodeficiency virus infection $\left(\mathrm{CD}_{4}<200 \mathrm{~mm}^{-3}\right)$, chemotherapy-radiation therapy (during the 6 months prior to ICU admission), and corticosteroid treatment in the 6 months before ICU admission (at least 2 weeks $>40 \mathrm{mg} \cdot \mathrm{d}^{-1}$ prednisolone, $>160 \mathrm{mg} \cdot \mathrm{d}^{-1}$ hydrocortisone, $>32 \mathrm{mg} \cdot \mathrm{d}^{-1}$ methylprednisolone, or $>6$ $\mathrm{mg} . \mathrm{d}^{-1}$ dexamethasone) and post-transplantation period].

\section{Data collection: infection and sepsis}

Patients with a confirmed or presumed infection during the 24-h study period were screened for the presence of systemic inflammatory response syndrome (SIRS), severe sepsis, and septic shock based on the modified consensus criteria of the American College of Chest Physicians and Society of Critical Care Medicine (ACCP/SCCM) 
[20]. The bedside clinicians decided whether the patient had a documented or presumed infection, according to the definitions of the International Sepsis Forum [21]. An extended documentation included the therapeutic intervention, culture and antibiotic susceptibility testing results, types of antimicrobial agent administered, presence of polymicrobial infection or multiple infection, length of ICU stay, and survival status after 1 month in patients with an infection. The survival status of patients who were discharged from the hospital within 30 days of the study day was obtained by follow-up phone calls, either to patients or their families.

Infections present upon admission or developed within $48 \mathrm{~h}$ of hospital admission were considered communityacquired. Infections occurring $>48 \mathrm{~h}$ after hospital admission were defined as hospital-acquired. Infections that developed at least $48 \mathrm{~h}$ after admission into the ICU were defined as ICU-acquired. A polymicrobial infection was defined as isolation of $\geq 2$ different microorganisms from the same site of infection. Multiple infection was defined as the presence of $\geq 2$ infections simultaneously in the same patient.

SIRS was defined as the occurrence of $\geq 2$ of the following criteria: white cell count of $>12,000$ cells. $\mathrm{mm}^{-3}$ or $<$ 4000 cells. $\mathrm{mm}^{-3}$ or $>10 \%$ immature forms; heart rate of $>$ 90 beats. $\mathrm{min}^{-1}$; temperature $>38{ }^{\circ} \mathrm{C}$ or $<36{ }^{\circ} \mathrm{C}$; and respiratory rate $>20$ per.min ${ }^{-1}$ or a partial pressure of carbon dioxide $<32 \mathrm{mmHg}$ during spontaneous breathing or the need for mechanical ventilation. In accordance with definitions of the ACCP/SCCM Consensus Conference Committee (SEPSIS-1), sepsis was defined as the presence (documented or presumed) of infection with SIRS [20]. Severe sepsis was defined as sepsis plus at least one sepsis-induced organ dysfunction, which was defined as follows: (a) acute encephalopathy: acute deterioration of neurologic condition (inattention, stupor, delirium, seizures, and coma), (b) hematological dysfunction: platelet count $<100,000 \mu \mathrm{L}^{-1}$, (c) respiratory dysfunction: $\mathrm{PaO}_{2} /$ fraction of inspired oxygen $<200$ if lungs are the site of infection or $<300$ if lungs were not the infection site, (d) renal dysfunction: urinary output $<0.5 \mathrm{~mL} . \mathrm{kg} . \mathrm{h}^{-1}$ for at least $2 \mathrm{~h}$ despite adequate volume resuscitation or serum creatinine $>2 \mathrm{mg} \cdot \mathrm{dL}^{-1}$ not attributable to chronic renal failure or $>50 \%$ increase from known baseline, (e) lactic acidosis: plasma lactate level $>2 \mathrm{mmol} \cdot \mathrm{L}^{-1}$, and (f) liver dysfunction: bilirubin $>2 \mathrm{mg} \cdot \mathrm{dL}^{-1}$ or international normalized ratio $>1.5$ in the absence of anticoagulant agents. Septic shock was defined as severe sepsis associated with refractory hypotension; despite at least $2 \mathrm{~h}$ of adequate volume resuscitation, a systolic blood pressure (SBP) $<90 \mathrm{mmHg}$ or a reduction of $\geq 40 \mathrm{mmHg}$ from baseline level or a mean arterial pressure $<70$ $\mathrm{mmHg}$ in the absence of other causes of hypotension or the need for vasopressors to maintain $\mathrm{SBP} \geq 90 \mathrm{mmHg}$.
This study was performed before the publication of the new sepsis definitions (SEPSIS-III) [22]. However, we determined patients who were in septic shock according to the SEPSIS-III definitions using our collected data. The clinical criteria to identify septic shock according to SEPSIS-III definitions were as follows: the need of vasopressor therapy to sustain a mean arterial pressure $\geq 65$ $\mathrm{mmHg}$ and serum lactate levels $>2 \mathrm{mmol} \cdot \mathrm{L}^{-1}$ persisting after adequate fluid replacement [22].

\section{Data source}

A detailed study protocol containing definitions for various items and instructions for data collection were sent to the study participants by e-mail. The principal investigators were easily accessible to all participants for all queries during data collection. Both bedside observation charts (demographic and clinical data) and electronic patient records (laboratory data regarding microbiology and antimicrobial resistance) could be used to capture data. All data were initially recorded using standardized paperbased forms. ICU and patient details were recorded in two different forms. The first form (Form A) was for the hospital and ICU details, such as hospital type, hospital and ICU bed counts, ICU type, total number of patients in the ICU on study day, nurse-to-patient ratios, number of ICU beds, and the percentage of ICU bed occupancy. The second form (Form B) was the case report form (CRF). The investigators also filled electronic CRFs on a specialized website (http://www.yogunbakim.org.tr/tybdaa/). All records were collected and evaluated by the principal investigators in the study center. After reviewing the data, the principal investigator asked the other investigators to fill out missing values.

\section{Statistical analysis}

All statistical analyses, except for the binary logistic regression analyses, were performed using SPSS version 20.0 (SPSS Inc, Chicago, IL, USA). Stata/MP 13.0 (StataCorp, College Station, TX, USA) for Windows was used for binary logistic regression analyses. Student's $t$ test and one-way analysis of variance with Tukey's post hoc test were used to compare normally distributed continuous variables. The Kruskal-Wallis test with Dunn's post hoc test and MannWhitney $U$ test were used to compare non-normally distributed continuous variables. According to the expected and observed frequency, Pearson's chi-square, Yates' chisquare, or Fisher's exact test was used for contingency tables. Pearson's chi-square or Monte Carlo simulation was applied for contingency tables that were larger than $2 \times 2$ according to the expected and observed frequency.

Two separate analyses were conducted to assess the relationship between carbapenem resistance and mortality. First, mortality rates were compared with the chi-squared test between patients infected with carbapenem-resistant 
(CR) and carbapenem-sensitive (CS) strains. For the second analysis, patients infected with Acinetobacter, Klebsiella, or Pseudomonas spp. were pooled. We initially compared demographics, comorbidities, APACHE II at admission day, sepsis severity, site of infection, and the length of stay prior to study day between patients who died and lived at 30 days. Variables with a $p$ value of $<0.2$ on univariate analysis were included in a multiple binary logistic regression analysis. The $\mathrm{CR}$ infection, polymicrobial infection, and multiple infection variables were included in the model regardless of statistical significance. The other variables included in the multiple logistic regression analysis were infection with Acinetobacter, Klebsiella, or Pseudomonas spp. Multiple logistic regression, with backward elimination method, was conducted to assess the predictors of mortality. A jackknifing resampling technique was used for multiple logistic regression to assess biases within the dataset. Multicollinearity was evaluated, with a variance inflation factor of $>10$ as an exclusion criteria. Box-Tidwell test was used to check the assumption of linearity of continuous predictors with logit-mortality. Significance levels for this test for age, APACHE II, SOFA, and the length of stay prior to study day were $0.938,0.082,0.711$, and 0.074 respectively. Variables with a $p$ value of $<0.05$ were retained in the final model. There was a limited number of patients infected with methicillin-sensitive/resistant Staphylococcus aureus; therefore, only chi-squared test was performed to compare the mortality rates between patients infected with methicillin-sensitive/resistant $S$. aureus.

A second multiple logistic regression analysis was performed to ascertain factors affecting mortality in the entire cohort of infected patients. Because of the hierarchical structure of the data, at first, three-level logistic regression analysis was considered to account for the within-cluster correlation of patient outcomes (at 30 days) in the entire cohort of infected patients. Levels were constructed as patients (level-1) nested within ICUs (level-2) and ICUs nested within hospitals (level-3). For all the selected independent variables, we calculated the intra-class correlation coefficients for the hospital (ICCh) and for the ICU level (ICCi) and corresponding design effects. When analyzing the association between mortality and variables, the ICCh ranged from 0.01 to 0.04 and the ICCi ranged from 0.05 to 0.11 (Additional file 1: Table S1). Design effects (i.e., indices of the extent of clustering effects) ranged from 1. 06 to 1.68 in all cases (Additional file 1: Table S1). Since design effects were lower than the critical value of two in all cases [23], single-level multiple logistic regression, with backward elimination method, was conducted to assess the predictors of mortality. A jackknifing resampling technique was used for multiple logistic regression to assess biases within the dataset. Variables considered for the multivariate modelling in the entire cohort included demographic data, comorbidities, admission category, severity scores (APACHE 2 score on admission, SOFA score on study day), clinical condition, presence of organ dysfunction and lactic acidosis, site of infection, type of microorganism, presence of polymicrobial infection and multiple infection, types of hospital and ICU, size of hospital, nurse to patient ratio, and therapies used. Variables with a $p$ value of $<0.2$ on univariate analysis were included into multiple binary logistic regression analysis. Polymicrobial infection and multiple infection variables were included in the model regardless of statistical significance. Multicollinearity was evaluated, with a variance inflation factor of $>10$ as an exclusion criteria. VIF values of selected variables were between 1.03 and 1.50. The Box-Tidwell test was used to check the assumption of linearity in continuous predictors with logit-mortality. Significance levels for this test for age, APACHE-II, and SOFA were all $0.757,0.981$, and 0.321 respectively. A $p$ value of $<0.05$ was considered significant. Adjusted odds ratios with 95\% confidence intervals (CIs) were reported.

\section{Results \\ Hospital and ICU characteristics}

ICUs $(n=132)$ from 94 hospitals, which were located in all 7 geographical regions of Turkey, participated in this study. The types of hospitals were as follows: university hospitals $(n=52 ; 55.3 \%)$, education and research hospitals $(n=24 ; 25.5 \%)$, state hospitals $(n=10 ; 10.6 \%)$, and private hospitals $(n=8 ; 8.5 \%)$. Approximately $71.2 \%$ of ICUs were mixed medical and surgical. In $63.5 \%$ of the participating ICUs, the nurse-to-patient ratio was 1:3 (44.6\%) or 1:4 (18. $9 \%$ ) (Table 1). The average percentage of ICU bed occupancy was $92.7 \% \pm 11.4 \%$.

The flowchart of the study is shown in Fig. 1.

\section{Prevalence and distribution of infection and sepsis}

Infection was present in 863 (57.5\%) of all patients. According to the 1992 consensus definitions, out of the 1499 patients included in the analysis, 163 (10.9\%) had sepsis (confirmed/presumed infection plus SIRS), 260 (17.3\%) had severe sepsis without shock, and 203 (13. $5 \%$ ) had septic shock (Fig. 1). According to the SEPSISIII definitions, 104 (6.9\%) patients were classified as having septic shock.

The infection rate was higher in hospitals with a bed capacity < 200 compared to that in hospitals with a higher bed capacity $(p \leq 0.05)$. However; the distribution of infected patients (i.e., pure infection, sepsis, severe sepsis, and septic shock) were not different among the hospital types $(p=0.169)$, and sizes $(p=0.068)$, and ICU types $(p=0.120)$. (Additional file 2 : Table S2).

The patient characteristics stratified according to the severity of sepsis and survival status are shown in Table 2. Patients who had septic shock on study day were older than patients with sepsis $(p=0.046)$ and had higher admission 
Table 1 Characteristics of participating centers

\begin{tabular}{|c|c|}
\hline Characteristics & All centers $(N, \%)$ \\
\hline Type of hospital & $94(100)$ \\
\hline University hospital & $52(55.3)$ \\
\hline Education and research hospital $^{a}$ & $24(25.5)$ \\
\hline State hospital & $10(10.6)$ \\
\hline Private hospital & $8(8.5)$ \\
\hline Specialty of ICU head & $132(100)$ \\
\hline Intensivist & $66(50)$ \\
\hline Anesthesiologist & $46(34.1)$ \\
\hline Surgeon & $8(6)$ \\
\hline Internist & $5(3.7)$ \\
\hline Neurologist & $3(2.2)$ \\
\hline Pulmonologist & $3(2.2)$ \\
\hline Interdisciplinary & $1(0.7)$ \\
\hline Type of ICU & $132(100)$ \\
\hline Mixed medical/surgical & $94(71.2)$ \\
\hline Surgical & $19(14.3)$ \\
\hline Medical & $16(12.1)$ \\
\hline Neurological & $3(2.2)$ \\
\hline Nurse-to-patient ratio & $132(100)$ \\
\hline $1: 2$ & $48(36.3)$ \\
\hline $1: 3$ & $59(44.6)$ \\
\hline $1: 4$ & $25(18.9)$ \\
\hline $\begin{array}{l}\text { The average percent }( \pm S D) \text {, and } \mathrm{Cl} 95 \% \text { of ICU } \\
\text { bed occupancy }\end{array}$ & $\begin{array}{l}92.7 \% \pm 11.4 \% \\
(91.5-93.0)\end{array}$ \\
\hline \multicolumn{2}{|c|}{$\begin{array}{l}\text { ICU intensive care unit, } S D \text { standard deviation, } C I \text { confidence interval } \\
{ }^{a} \text { Education and research hospitals are different from university hospitals, } \\
\text { because they conduct postgraduate medical education and research. The } \\
\text { former only provides specialty training (i.e., doctors who specialize after } \\
\text { graduating from a medical faculty), whereas the latter provides specialty and } \\
\text { medical training concurrently }\end{array}$} \\
\hline
\end{tabular}

APACHE II scores than other infected patients without shock $(p<0.05)$. Patients with severe sepsis or septic shock had higher SOFA scores than patients without severe sepsis on study day $(p \leq 0.001)$, and SOFA scores of patients with septic shock were higher than severe septic patients without shock (Table 2, $p=0.001$ ). The most frequent comorbid condition was chronic respiratory failure, followed by cerebrovascular accident and congestive heart failure in infected patients. The rate of severe sepsis (with or without shock) was $71.6 \%$ in infected patients who have immunosuppression as a comorbid condition.

Approximately $32.8 \%$ of all infected patients had community-acquired infections, whereas $54.4 \%$ of infected patients had nosocomial infections in the present study (Table 3). The most common site of infection was the respiratory system $(71.6 \%)$, followed by the bloodstream (8.9\%) and urinary system (7.8\%) in infected patients. Except for skin/soft tissue infections, the distribution of infections was similar among patients with different clinical conditions, including infection alone, infection plus SIRS, severe sepsis, and septic shock. None of the patients with skin/soft tissue infections had septic shock on study day (Table 3).

Of the $503(58.3 \%)$ of infected patients had positive microbial isolates. 78.7 of the positive isolates were gram negative, $15.5 \%$ were gram positive, $4.9 \%$ were fungi, and $0.7 \%$ were viruses (Table 4 ). Acinetobacter spp. were the most common isolated pathogen (33.7\%), followed by Pseudomonas spp. (16.4\%) and Klebsiella spp. (16.0\%; Table 4). About $74.8 \%$ of Acinetobacter spp. isolates, 39. $0 \%$ of Klebsiella spp. isolates, and $26.5 \%$ of Pseudomonas spp. isolates were resistant to carbapenem. It was observed that $2.7 \%$ of Klebsiella spp. isolates, $2.6 \%$ of Pseudomonas spp. isolates, and $2.1 \%$ of Acinetobacter spp. isolates were resistant to colistin. About $57.0 \%$ of the gram-positive isolates were $S$. aureus, and $75.4 \%$ of the $S$. aureus isolates were identified as methicillin-resistant (MRSA). The distribution of microorganisms isolated from culturepositive-infected patients according to their clinical conditions is shown in Table 4. The proportions of isolated microorganisms were not significantly different among patients with different clinical conditions, including infection alone, infection + SIRS, severe sepsis, and septic shock, when evaluated using Monte Carlo simulation.

\section{Therapies}

All infected patients were receiving at least one antimicrobial agent on study day. The most frequently administered antimicrobials to patients with infections on study day were as follows: carbapenems $(n=322 ; 37$. $3 \%)$, followed by colistin ( $n=180 ; 20.8 \%)$, cephalosporins $(n=120 ; 13.9 \%)$, fluoroquinolones $(n=119 ; 13.7 \%)$, glycopeptides $(n=90 ; 10.4 \%)$, antifungals $(n=70 ; 8.1 \%)$, tigecycline $(n=65 ; 7.5 \%)$, beta lactam-betalactamase inhibitors $(n=62 ; 7.20 \%)$, linezolid ( $n=57 ; 6.6 \%)$, antivirals $(n=54 ; 6.2 \%)$, clindamycin $(n=36 ; 4.2 \%)$, metronidazole/ornidazole $(n=21 ; 2.4 \%)$, aminoglycosides $(n=15 ; 1.7 \%)$, and others $(n=25 ; 2.9 \%)$.

The monitoring methods and therapies used in patients with severe sepsis (with or without shock) on study day are shown in the Additional file 3: Table S3. Mechanical ventilation (MV) was required in $87.2 \%$ of patients with severe sepsis. Inotropic/vasopressor agents, corticosteroids, and renal replacement therapy (RRT) were the other most frequently used life support therapies in patients with severe sepsis $(49.0 \%, 26.7 \%$, and $23.7 \%$, respectively). Although the lactate level was recorded on study day in all infected patients according to the requirements of the study protocol, the lactate levels were measured as a monitoring method in only $79.9 \%$ of patients with severe sepsis (Additional file 3: Table S3). 


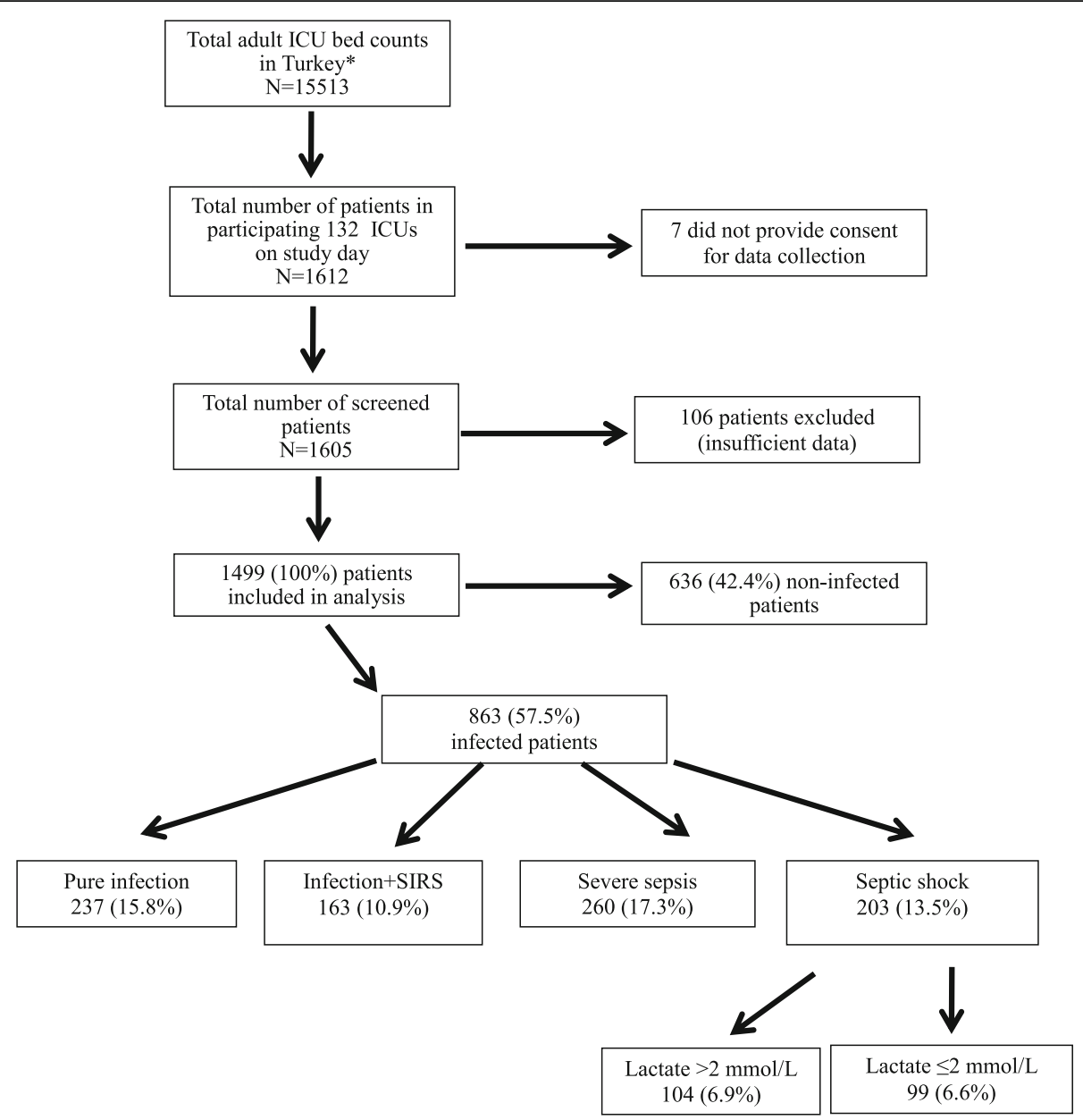

Fig. 1 Flow chart of study participants. ICU intensive care unit, SIRS systemic inflammatory response syndrome., Following exclusion of cardiovascular, coronary, and pediatric ICUs

\section{Organ dysfunction and mortality}

Respiratory and renal dysfunction were the most common organ dysfunctions among patients with severe sepsis and septic shock (Table 2). However, renal dysfunction $(p \leq 0$. $001)$, neurologic dysfunction $(p \leq 0.001)$, and lactic acidosis $(p=0.005)$ were significantly more common in septic shock patients than in severe septic patients without shock (Table 2). The mortality rates of severe sepsis and septic shock (55.7\% and $70.4 \%$, respectively) were significantly higher than that in patients with infection alone and infection plus SIRS (24.8\% and 31.3\%, respectively) ( $p$ $\leq$ 0.001; Table 2).

Septic shock was associated with a higher number of organ dysfunctions $(4.4 \pm 1.3$ and $3.7 \pm 1.5$, respectively) and mortality rate $(75.9 \%$ and $70.4 \%$, respectively) when septic shock was defined according to SEPSIS-III definition compared to the SEPSIS-I definitions (Table 2). The sensitivity and specificity of septic shock for mortality rate were higher $(80.4 \%$ and $94 \%$, respectively) when the SEPSIS-III definitions were used in comparison to the SEPSIS-I definitions (64.2\% and $87.4 \%$, respectively).

\section{Antibiotic resistance and mortality}

As shown in Fig. 2, the rate of mortality in those with MRSA infections was not statistically different from that of methicillin-sensitive $S$. aureus infections. The mortality rate was also not different between CR and CS strains (Fig. 2).

Patients infected with Acinetobacter spp., Klebsiella spp., or Pseudomonas spp. were pooled. A binary logistic regression analysis was performed to identify risk factors for mortality among patients infected with Acinetobacter spp., Klebsiella spp., or Pseudomonas spp. Variables with a $p$ value $<0.2$ on univariate analysis (Additional file 4 , Table S4) were incorporated into the multiple binary logistic regression model The $\mathrm{CR}$ infection, polymicrobial infection, and multiple infection variables were included in the model regardless of statistical significance. The other variables included in the binary logistic regression analysis were 
Table 2 Patient characteristics and mortality ratio stratified according to sepsis severity

\begin{tabular}{|c|c|c|c|c|c|c|}
\hline & $\begin{array}{l}\text { All infected } \\
\text { patients } \\
n=863\end{array}$ & $\begin{array}{l}\text { Infection } \\
n=237\end{array}$ & $\begin{array}{l}\text { Infection } \\
+ \text { SIRS } \\
n=163\end{array}$ & $\begin{array}{l}\text { Severe sepsis } \\
\text { without shock } \\
n=260\end{array}$ & $\begin{array}{l}\text { Septic shock } \\
\text { (SEPSIS I) } \\
n=203\end{array}$ & $\begin{array}{l}\text { Septic shock } \\
\text { (SEPSIS-III) } \\
n=104\end{array}$ \\
\hline Age, yrs & $69(55-79)$ & $70(58-80)$ & $64(52-78)$ & $69(50-78)$ & $70(58-79)^{*}$ & $67(57-76)$ \\
\hline Female/male, $\mathrm{n}$ & $366 / 497$ & $104 / 133$ & $68 / 95$ & $108 / 152$ & $86 / 117$ & $46 / 58$ \\
\hline APACHE II score at ICU admission ${ }^{\text {b }}$ & $21(16-28)$ & $20(15-24)$ & $18.0(15-24)$ & $21.5(17-28)^{\ddagger}$ & $25(19-31)^{c}$ & $25.5(19.7-31.2)$ \\
\hline SOFA score ${ }^{b}$ & $7(5-11)$ & $6(4-9)$ & $5(3-8)$ & $8(6-11)^{f}$ & $10(7-13)^{f_{1}+}$ & $11(8-14)$ \\
\hline \multicolumn{7}{|l|}{ Comorbidities, n (\%) } \\
\hline Chronic respiratory disease & $192(22.3)$ & $52(21.9)$ & $39(23.9)$ & $57(21.9)$ & $44(21.7)$ & $24(23.0)$ \\
\hline Cerebrovascular accident & $118(13.6)$ & $34(14.3)$ & $29(17.7)$ & $36(13.8)$ & $19(9.4)$ & $12(11.5)$ \\
\hline Congestive heart failure & $98(11.3)$ & $21(8.4)$ & $18(10.4)$ & $0(10.0)$ & $29(17.2)$ & $18(17.3)$ \\
\hline Chronic renal failure & $95(11)$ & $23(9.7)$ & $18(11)$ & $28(10.7)$ & $26(12.8)$ & $14(13.5)$ \\
\hline Solid organ malignancy & $81(9.3)$ & $17(7.1)$ & $14(8.5)$ & $24(9.2)$ & $26(12.8)$ & $15(14.4)$ \\
\hline Immunosuppression & $67(7.7)$ & $9(3.8)$ & $10(6.1)$ & $22(8.4)^{\varnothing}$ & $26(12.8)^{\#}$ & $21(20.1)$ \\
\hline Liver disease & $22(2.5)$ & $5(2.1)$ & $1(0.6)$ & $7(2.6)$ & $9(4.4)$ & $7(6.7)$ \\
\hline Alcoholism & $17(1.9)$ & $6(2.5)$ & $3(1.8)$ & $3(1.2)$ & $5(2.5)$ & $2(1.9)$ \\
\hline Number of acute organ dysfunctions (mean \pm SD) & & - & - & $2.0 \pm 1.0$ & $3.7 \pm 1.5^{\&}$ & $4.4 \pm 1.3$ \\
\hline \multicolumn{7}{|l|}{ Organ dysfunction, n (\%) } \\
\hline Respiratory & $271(31.4)$ & - & - & $147(56.5)$ & $124(61.1)$ & $74(71.2)$ \\
\hline Renal & $223(25.8)$ & - & - & $104(40.0)$ & $119(58.6)^{\&}$ & $70(67.3)$ \\
\hline Neurologic & $171(19.8)$ & - & - & $70(26.9)$ & $101(49.8)^{\&}$ & $56(53.8)$ \\
\hline Liver & $133(15.4)$ & - & - & $70(26.9)$ & $63(31.0)$ & $38(36.5)$ \\
\hline Hematologic & $118(13.6)$ & - & - & $64(24.6)$ & $54(26.6)$ & $36(34.6)$ \\
\hline Lactic acidosis (> 2 mmol. $\mathrm{L}^{-1}$ ), n (\%) & $174(20.2)$ & - & - & $83(31.9)$ & $91(44.8)^{\epsilon}$ & $104(100)$ \\
\hline \multicolumn{7}{|l|}{ Therapies, n (\%) } \\
\hline RRT & $152(17.6)$ & $21(8.9)$ & $22(13.5)$ & $53(21.5)$ & $56(26.1)$ & $28(26.9)$ \\
\hline MV & $715(82.9)$ & $176(74.3)$ & $123(75.5)$ & $227(87.3)$ & $189(93.1)$ & $94(90.4)$ \\
\hline Length of stay, day ${ }^{\mathrm{e}}$ & $27(13-45)$ & $30(13-47)$ & $27(13-48)$ & $30(14.2-45.7)$ & $22\left(11.2-36.5^{)}\right.$ & $17(10-30)$ \\
\hline Mortality, n (\%) & $401(46.1)$ & $61(24.8)$ & $52(31.2)$ & $145(55.7)^{f}$ & $143(70.4)^{f_{,}+}$ & 79 (75.9) \\
\hline
\end{tabular}

Data are presented as median (25th-75th percentiles), if not otherwise specified

SIRS systemic inflammatory response syndrome, APACHE // acute physiology and chronic health evaluation, ICU intensive care unit, SOFA sequential organ failure assessment, $S D$ standard deviation, $R R T$ renal replacement therapy, $M V$ mechanical ventilation

a Patients with septic shock based on SEPSIS-III definitions are covered in the septic shock group based on the SEPSIS-1 definition; data presented in this column were not included in any statistically analysis

${ }^{\mathrm{b}} 8$ and ${ }^{\mathrm{e}} 56$ missing values

${ }^{*} p=0.046$, compared with infection + SIRS group

$c_{p} \leq 0.05$, compared with infection, infection + SIRS, and severe sepsis groups

${ }^{\ddagger} p=0.042$, compared with infection + SIRS groups

${ }^{f} p \leq 0.001$, compared with infection and infection + SIRS groups

${ }^{+} p=0.001$, compared with severe sepsis groups

$\varnothing_{p}=0.031$, compared with infection group

${ }^{c} p=0.027$, compared with infection group

$\# p \leq 0.05$, compared with infection and infection + SIRS groups

$\&_{p} \leq 0.001$, compared with severe sepsis groups

$\epsilon_{p}=0.005$, compared with severe sepsis groups

infection with Acinetobacter, Klebsiella, or Pseudomonas spp. Based on the multiple binary logistic regression analysis, it was confirmed that carbapenem resistance was not an independent risk factor for mortality $(p=0.587)$ after adjusting for other variables in the model. However, age, severe sepsis, septic shock, and RRT were independent risk factors for mortality (Table 5). Infection with Klebsiella spp. was associated with a lower mortality among patients infected with Acinetobacter, Klebsiella, or Pseudomonas spp. (Table 5).

\section{Factors associated with mortality in the entire cohort of infected patients}

Comparative analyses of the variables in relation to mortality in all infected patients are shown in the Additional file 5: 
Table 3 Origin and type of infection in infected patients

\begin{tabular}{|c|c|c|c|c|c|c|}
\hline & $\begin{array}{l}\text { All infected } \\
\text { patients } \\
\mathrm{n}=863\end{array}$ & $\begin{array}{l}\text { Infection } \\
n=237\end{array}$ & $\begin{array}{l}\text { Infection } \\
+ \text { SIRS } \\
n=163\end{array}$ & $\begin{array}{l}\text { Severe sepsis } \\
\text { without shock } \\
n=260\end{array}$ & $\begin{array}{l}\text { Septic shock } \\
\text { (SEPSIS I) } \\
\mathrm{n}=203\end{array}$ & $\begin{array}{l}\text { Septic shock } \\
\text { (SEPSIS-III) } \\
n=104\end{array}$ \\
\hline \multicolumn{7}{|l|}{ Origin of infection, n (\%) } \\
\hline Community-acquired & $285(32.8)$ & $85(35.8)$ & $52(31.9)$ & $86(33)$ & $62(30.5)$ & $30(28.8)$ \\
\hline Hospital-acquired & $259(30)$ & $59(24.8)$ & $52(31.9)$ & $75(28.8)$ & $73(35.9)$ & $38(36.5)$ \\
\hline ICU-acquired & $211(24.4)$ & $62(26.1)$ & $44(26.9)$ & $64(24.6)$ & $41(20.1)$ & $21(20.1)$ \\
\hline Unknown & $108(12.5)$ & $31(13.0)$ & $15(9.2)$ & $35(13.4)$ & $27(13.3)$ & $15(14.4)$ \\
\hline \multicolumn{7}{|l|}{ Type of infection ${ }^{\mathrm{b}}, \mathrm{n}(\%)$} \\
\hline Respiratory & $618(71.6)$ & $158(66.6)$ & $118(72.3)$ & $188(72.3)$ & $154(75.9)$ & $85(81.7)$ \\
\hline Bloodstream & $77(8.9)$ & $28(11.8)$ & $15(9.2)$ & $22(8.5)$ & $12(5.9)$ & $9(8.6)$ \\
\hline Renal/urinary & $67(7.8)$ & $21(8.8)$ & $12(7.4)$ & $19(7.3)$ & $15(7.3)$ & $7(6.7)$ \\
\hline Catheter-related & $56(6.5)$ & $17(7.1)$ & $8(4.9)$ & $18(6.9)$ & $13(6.4)$ & $6(5.7)$ \\
\hline Intra-abdominal & $49(5.6)$ & $10(4.2)$ & $9(5.5)$ & $12(4.6)$ & $18(8.8)$ & $13(12.5)$ \\
\hline Surgical & $32(3.7)$ & $6(2.5)$ & $5(3.0)$ & $9(3.4)$ & $12(5.9)$ & $3(2.8)$ \\
\hline Skin/soft tissue & $24(2.7)$ & $6(2.5)$ & $8(4.9)$ & $10(3.8)$ & $0(0)^{*}$ & $0(0)$ \\
\hline Others & $22(2.5)$ & $2(0.8)$ & $6(3.7)$ & $9(3.4)$ & $5(2.5)$ & $3(2.9)$ \\
\hline
\end{tabular}

SIRS systemic inflammatory response syndrome, ICU intensive care unit

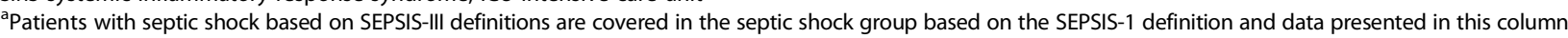
were not included in any statistically analysis

${ }^{b}$ Percentages do not necessarily equal 100 because patients may have had $>1$ type of infection

${ }^{*} p<0.05$, compared with infection, infection + SIRS, and severe sepsis groups

Table S5. By univariate analysis, age, APACHE-II score at admission, SOFA score on study day, and the presence of comorbid conditions, including congestive heart failure, chronic renal failure, solid organ malignancy, chronic liver disease, and immunosuppression, were associated with mortality. Based on the univariate analysis, the presence of any acute organ dysfunctions (i.e., respiratory, renal, hepatic, neurologic, and hematologic dysfunction), hyperlactatemia, the severity of sepsis, Acinetobacter spp. infection, Pseudomonas spp. infection, Candida spp. infection, polymicrobial infection, RRT, and MV were also associated with mortality (Additional file 5: Table S5). Variables with a $p$ value $<0.2$ on univariate analysis were incorporated into the multiple logistic regression model. In the multiple logistic regression analysis, APACHE-II scores at ICU admission, SOFA scores on study day, older age, solid organ malignancy, the presence of severe sepsis, or septic shock, Candida spp. infection, RRT, and a nurse-to-patient ratio of 1:4 (compared with a nurse-to-patient ratio of 1:2) were independent predictors of mortality in the entire group of infected patients (Table 6).

\section{Discussion}

In this large-scale, multicenter study, we observed a high incidence of infection and sepsis in Turkish ICUs. Moreover, the mortality rate of severe sepsis and septic shock was unacceptably high $(55.7 \%$ and $70.4 \%$, respectively). Although the prevalence of carbapenem resistance was high in Turkish ICUs, it was not associated with a higher risk for mortality. However, age, APACHE-II score at ICU admission, SOFA score on study day, solid organ malignancy, the presence of severe sepsis or septic shock, Candida spp. infection, RRT, and a nurse-to-patient ratio of 1:4 were found to be predictors of mortality.

According to our study, the infection rate was $57.5 \%$ and about $54.4 \%$ of the infections were nosocomial in Turkish ICUs. In a previous, multicenter, point prevalence study performed in September 2004, Esen et al. reported that 48.7\% of patients were infected in Turkish ICUs and, similar to our findings, the most frequent site of infection was the respiratory system, followed by bloodstream and urinary tract infections [24]. In the international study of the prevalence and outcomes of infection in intensive care units (EPIC II), the prevalence of ICU infections was higher in countries that allocated a lower percentage of their gross domestic product on healthcare [25]. Many factors, including infection control practices, educational strategies, national antibiotic and public health policy can affect infection rates [25]. Although healthcare spending in Turkey has increased rapidly since 2002, Turkey remains the country with the lowest health expenditure in the OECD [26]. Turkey also has fewer critical human resources for healthcare compared to developed countries. A challenge for infection control in healthcare facilities in Turkey is a low nurse-to-patient ratio [27]. One of the most important findings of this study was that the low nurse-to-patient ratio in ICUs was an independent risk factor for mortality in infected patients. Some researchers observed no association [28, 29] while some found 
Table 4 Distribution of microorganisms isolated from culture-positive-infected patients according to clinical condition

\begin{tabular}{|c|c|c|c|c|c|}
\hline & $\begin{array}{l}\text { All } \\
(n=863)\end{array}$ & $\begin{array}{l}\text { Infection } \\
(n=237)\end{array}$ & $\begin{array}{l}\text { Infection + SIRS } \\
(\mathrm{n}=163)\end{array}$ & $\begin{array}{l}\text { Severe sepsis } \\
\text { without shock } \\
(n=260)\end{array}$ & $\begin{array}{l}\text { Septic shock } \\
(n=203)\end{array}$ \\
\hline Culture-positive-infected patients, n (\%) & $503(58.3)$ & $131(55.3)$ & $83(50.9)$ & $154(59.2)$ & $135(66.5)$ \\
\hline Isolated microorganisms ${ }^{\mathrm{a}}, \mathrm{n}(\%)$ & $686(100)$ & $161(100)$ & $126(100)$ & 213(100) & 186(100) \\
\hline Gram negative & $540(78.7)$ & $124(77)$ & $99(78.5)$ & $162(76)$ & $155(83.3)$ \\
\hline Acinetobacter spp. & $231(33.7)$ & $56(34.7)$ & $42(33.3)$ & $70(32.8)$ & $63(33.9)$ \\
\hline Carbapenem-resistant & $173(25.2)$ & $37(22.9)$ & $32(25.3)$ & $51(23.9)$ & $53(28.5)$ \\
\hline Colistin-resistant & $5(0.7)$ & $1(0.6)$ & $1(0.8)$ & $1(0.5)$ & $2(1.0)$ \\
\hline Pseudomonas spp. & $113(16.4)$ & $22(13.6)$ & $22(17.4)$ & $39(18.3)$ & $30(16.1)$ \\
\hline Carbapenem-resistant & $30(4.4)$ & $6(3.7)$ & $8(6.3)$ & $10(4.7)$ & $6(3.2)$ \\
\hline Colistin-resistant & $3(0.4)$ & $0(0.0)$ & $1(0.8)$ & $0(0.0)$ & $2(1.0)$ \\
\hline Klebsiella spp. & $110(16)$ & $23(14.2)$ & $20(15.8)$ & $26(12.2)$ & $41(22.0)$ \\
\hline Carbapenem-resistant & $43(6.3)$ & $10(6.2)$ & $8(6.3)$ & $7(3.3)$ & $18(9.7)$ \\
\hline Colistin-resistant & $3(0.4)$ & $0(0.0)$ & $1(0.8)$ & $0(0.0)$ & $2(1.0)$ \\
\hline Escherichia coli & $37(5.4)$ & $12(7.4)$ & $6(4.7)$ & $8(3.7)$ & $11(5.9)$ \\
\hline Serratia marcescens & $12(1.7)$ & $3(1.8)$ & $2(1.5)$ & $6(2.8)$ & $1(0.5)$ \\
\hline Proteus spp. & $10(1.4)$ & $3(1.8)$ & $0(0)$ & $6(2.8)$ & $1(0.5)$ \\
\hline Enterobacter spp. & $8(1.1)$ & $2(1.2)$ & $0(0)$ & $4(1.8)$ & $2(1.0)$ \\
\hline Others & $19(2.7)$ & $3(1.8)$ & $7(5.5)$ & $3(1.4)$ & $6(3.2)$ \\
\hline Gram positive & $107(15.5)$ & $26(16.1)$ & $21(16.6)$ & $41(19.2)$ & 19 (10.2) \\
\hline Staphylococcus aureus & $61(8.9)$ & $16(9.9)$ & $13(10.3)$ & $20(9.8)$ & $12(6.4)$ \\
\hline MRSA & $46(6.7)$ & $13(8.0)$ & $12(9.5)$ & $12(5.6)$ & $9(4.8)$ \\
\hline Enterococcus spp. & $38(5.5)$ & $9(5.6)$ & $8(6.3)$ & $14(6.5)$ & $7(3.7)$ \\
\hline VRE & $3(0.4)$ & $1(0.6)$ & $0(0)$ & $2(0.9)$ & $0(0)$ \\
\hline Others & $8(1.2)$ & $1(0.6)$ & $0(0)$ & $7(3.3)$ & $0(0)$ \\
\hline Fungi & $34(4.9)$ & & & & \\
\hline Candida spp. & $32(4.7)$ & $8(4.9)$ & $6(4.7)$ & $8(3.7)$ & $10(5.4)$ \\
\hline Aspergillus spp. & $2(0.3)$ & $0(0)$ & $0(0)$ & $0(0)$ & $2(1.0)$ \\
\hline Virus & $5(0.7)$ & & & & \\
\hline H1N1 & $5(0.7)$ & $3(1.9)$ & $0(0)$ & $2(0.9)$ & $0(0)$ \\
\hline
\end{tabular}

SIRS systemic inflammatory response syndrome, MRSA methicillin-resistant Staphylococcus aureus VRE vancomycin-resistant Enterococcus ${ }^{\text {a }}$ atients may have more than one microorganism isolated

significant associations [30, 31] between the nurse-to-patient ratio and mortality rate in previous studies. The optimal nurse-to-patient ratios have not yet been determined based on scientific evidence. In the present study, the odds of death was increased by 1.95 (95\% CI, 1.2-3.0) when the nurse-to-patient ratio was 1:4 instead of $1: 2$ in infected patients. In a recent multicenter, longitudinal study, the risk of death increased by 3.5 (95\% CI, 1.3-9.1) in the ICU when the patient to nurse ratio was $>2.5$ [30]. Further studies are needed to demonstrate the optimal nurse-to-patient ratio in the ICU.

The prevalence of sepsis, severe sepsis and septic shock In the present study, the prevalence of sepsis, severe sepsis, and septic shock was $10.9 \%, 17.3 \%$, and $13.5 \%$, respectively, in infected patients according to the 1992 definitions (SEPSIS-I). The total prevalence of severe sepsis was high (30. $9 \%$ with or without shock) in the present study. The prevalence of severe sepsis was found to be $26 \%$ and $22 \%$ in two single-day, point prevalence studies performed in 2012 and 2013, respectively, in Polish ICUs [32]. According to point prevalence surveys, the prevalence of severe sepsis was 29 . $6 \%$ in Brazilian ICUs on a single day 2015 [33] and 17.9\% in German ICUs in 2013 [3].

The percentage of sepsis in point prevalence studies changes according to the availability of ICU beds (34). It was claimed that the high frequency of sepsis in ICUs in some countries, such as Brazil and the United Kingdom (UK), are due to a shortage of ICU beds because only the most seriously ill patients (i.e., those with sepsis and 


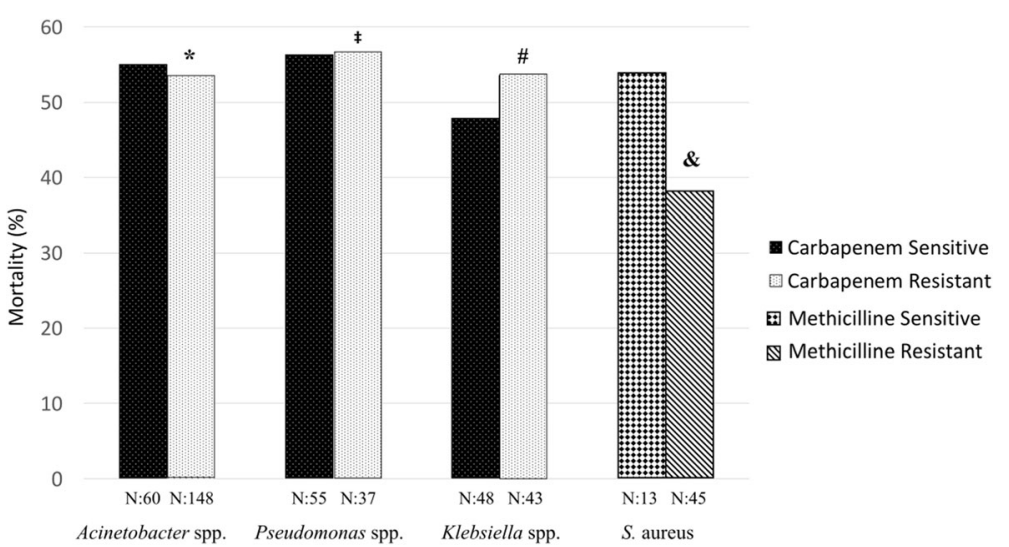

Fig. 2 Antibiotic susceptibility pattern of microorganisms and survival status at 30 days. Mortality ratio was not different among antibiotic-sensitive and -resistant strains when evaluated by chi-squared test. ${ }^{*} p=0.832$, compared with carbapenem-sensitive Acinetobacter spp. ${ }^{\ddagger} p=0.970$, compared with carbapenem-sensitive Pseudomonas spp. ${ }^{\#} p=0.595$, compared with carbapenem-sensitive Klebsiella spp. ${ }^{\circledR} p=0.474$, compared with methicillinsensitive S. aureus

multiorgan failure) can be admitted [34, 35]. Although the ICU bed counts in Turkey can be comparable to that of countries in Western Europe (www.saglikistatistikleri.gov. tr $>$ SIY-2015), there is always a high demand for ICU beds in Turkey, mostly due to a lack of post-ICU care facilities and legal support to limit life-support interventions for terminally ill patients. Therefore, Turkish ICUs are mostly overcrowded and only the sickest patients can be admitted. This situation also causes delay in treatment, preventing the early identification and intervention of sepsis, which may worsen outcomes [36].

\section{Mortality of severe sepsis}

In a recent, international, multicenter, prevalence study on sepsis (IMPRESS study) [37], the average mortality rate of

Table 5 Risk factors for 30-day mortality in patients infected with Acinetobacter, Pseudomonas, or Klebsiella spp

\begin{tabular}{llll}
\hline & Odds ratio & $95 \% \mathrm{Cl}$ & $p$ value \\
\hline $\begin{array}{l}\text { Age, per year increase } \\
\begin{array}{l}\text { Clinical condition } \\
\text { Infection }\end{array}\end{array}$ & 1.02 & $1.012-1.040$ & $<0.001$ \\
$\quad$ Infection + SIRS & 1.983 & $0.960-4.096$ & 0.064 \\
$\quad \begin{array}{l}\text { Severe sepsis without shock } \\
\text { Septic shock }\end{array}$ & 3.072 & $1.603-5.889$ & $<0.001$ \\
Infections & 7.587 & $3.765-15.287$ & $<0.001$ \\
$\quad$ Klebsiella spp. & 0.550 & $0.316-0.960$ & 0.035 \\
Therapies & & & \\
$\quad$ RRT & 1.903 & $1.031-3.513$ & 0.040 \\
\hline
\end{tabular}

Model log-likelihood: -208.427; F: 8.55; $p \leq 0.001$. Hosmer-Lemeshow $X^{2}=10.2$; $p=0.247$

$\mathrm{Cl}$ confidence interval, SIRS systemic inflammatory response syndrome, RRT renal replacement therapy

aReference group severe sepsis was $28 \%$; however, there were large differences in the mortality rates among North America, South/ Central America, and Eastern Europe (24.2\%, 36.7\%, and $44 \%$, respectively). The 30 -day mortality rate of severe sepsis and septic shock was unacceptably high (55.8\% and $70 \%$, respectively) in the present study. Although there is no previous multicenter study regarding sepsis in Turkey, a very high ICU mortality rate of $87.3 \%$ was reported in a single-center retrospective study from a university hospital in Turkey based on the review of data from 63 sepsis patients from 2002 to 2003 [38]. We did not investigate compliance with sepsis bundles in Turkish ICUs in this study. However, in a previous multicenter study, it was found that physicians who were routinely in charge of sepsis patients in Turkey had poor knowledge of the sepsis bundles [39]. Delayed treatment and poor compliance with sepsis bundles are probably the most important causes of high mortality in patients with severe sepsis in Turkish ICUs. This study was performed in the winter (January 27), which could have contributed to the high frequency and mortality rate of sepsis as shown in previous studies [40].

High mortality rates for sepsis and septic shock, similar to that of Turkey, have been reported in other middleand low-income countries. According to point prevalence surveys, the overall mortality rate of severe sepsis was 55 . $7 \%$ in Brazilian ICUs, $64.6 \%$ in Indian ICUs, and $80 \%$ in Pakistan ICUs [33, 41, 42]. According to a single-center cohort study, the mortality ratio of septic shock was $82 \%$ in Tunisia [43].

\section{Carbapenem resistance and mortality}

The carbapenem resistance rates in the present study (Acinetobacter spp., 74.9\%; Klebsiella spp., 39.1\%; and Pseudomonas spp., 26.5\%) were higher than that of 
Table 6 Risk factors for 30-day mortality in all infected patients

\begin{tabular}{|c|c|c|c|}
\hline & Odds ratio & $95 \% \mathrm{Cl}$ & $p$ value \\
\hline Age, per year increase & 1.02 & $1.012-1.031$ & $<0.001$ \\
\hline $\begin{array}{l}\text { APACHE II score at admission, } \\
\text { per point increase }\end{array}$ & 1.02 & $1.006-1.036$ & 0.005 \\
\hline $\begin{array}{l}\text { SOFA score on study day, } \\
\text { per point increase }\end{array}$ & 1.115 & $1.067-1.165$ & $<0.001$ \\
\hline \multicolumn{4}{|l|}{ Comorbid condition } \\
\hline Solid organ malignancy & 1.924 & $1.081-3.425$ & 0.026 \\
\hline \multicolumn{4}{|l|}{ Clinical condition } \\
\hline \multicolumn{4}{|l|}{ Infection $^{a}$} \\
\hline Infection + SIRS & 1.617 & $0.986-2.651$ & 0.057 \\
\hline Severe sepsis & 4.659 & $2.875-7.548$ & $<0.001$ \\
\hline Septic shock & 3.326 & $2.152-5.141$ & $<0.001$ \\
\hline \multicolumn{4}{|l|}{ Infections } \\
\hline Candida spp. & 3.526 & $1.437-8.653$ & 0.006 \\
\hline \multicolumn{4}{|l|}{ Therapies } \\
\hline RRT & 2.675 & $1.702-4.206$ & $<0.001$ \\
\hline \multicolumn{4}{|l|}{ Nurse to patient ratio } \\
\hline \multicolumn{4}{|l|}{$1: 2^{a}$} \\
\hline $1: 3$ & 1.43 & $0.977-2.014$ & 0.066 \\
\hline $1: 4$ & 1.958 & $1.259-3.043$ & 0.003 \\
\hline
\end{tabular}

Model log-likelihood: -474.943; F: 15.15; $p \leq 0.001$. Hosmer-Lemeshow $X^{2}=10.3$; $p=0.245$

Cl confidence interval, APACHE II acute physiology and chronic health evaluation, SOFA sequential organ failure assessment, SIRS systemic inflammatory response syndrome, $R R T$ renal replacement therapy

${ }^{\mathrm{a}}$ Reference group

previous reports from most of European countries and the US [44, 45]. Carbapenem resistance was not found to be an independent risk factor for mortality in the present study, which may be explained in part by the fact that there is widespread use of polymyxins for treating $C R$ infections in Turkey. In the present study, one in every five infected patients received colistin on study day. In some previous studies, more deaths were observed among patients infected with CR Enterobacteriaceae than those with CS Enterobacteriaceae [16, 17]; however, there was no significant difference in mortality rates for patients infected with CR and CS Enterobacteriaceae in some other studies $[18,19]$. In the present study, infections were defined according to the definitions of the International Sepsis Forum Consensus Conference [21]. However, despite this, there might be differences in the diagnosis of infection among different centers and researchers. Especially regarding VAP, it may not always be possible to differentiate between colonization and infection. These factors may have contributed to the lack of difference in mortality rates for the CR and CS strains in this study. Another explanation why carbapenem resistance was not found as a risk factor for mortality in this study could be the low percentage of bacteremia cases $(9.5 \%$ among patients infected with Acinetobacter spp., Klebsiella spp., or Pseudomonas spp.). A significant difference in the death rates was not detected among patients with infections other than bacteremia, undetermined infections, or a low percentage of bacteremia cases $[18,19]$. We did not report the appropriate empirical antibiotic treatment in this study, which is a limitation of the study. However, the likelihood of using inappropriate initial antibiotics in patients infected with CR strains is significantly higher than that of those infected with CS strains [46]. In the present study, the mortality rate was already similar between patients infected with CR and CS strains even without considering appropriate initial antibiotic treatment.

\section{Candida infections and mortality}

Candida infections were found to be independent risk factors for mortality in this study. Although infection with Acinetobacter spp. was significantly higher in nonsurvivors than survivors, infection with Acinetobacter spp. was not an independent predictor of mortality after adjusting for confounders. Candida bloodstream infections, the majority of nosocomial fungal infections, are a significant cause of mortality in the ICU $[47,48]$. According to data from the EUROBACT study [48], fungemia ( $82.6 \%$ are caused by Candida spp.) was associated with higher mortality. In the present study, 53.6\% of Candida infections were bloodstream infections. There was a longer delay in initiation of antifungal treatment for fungemia than there was for antibiotics for bacteremia [48]. In the present study, appropriate initial antifungal treatment was not considered which could have contributed to the finding of Candida infections as an independent risk factor for mortality. Nevertheless, the results of studies investigating the benefit of early antifungal treatment in patients with candidemia are contradictory $[48,49]$.

\section{Septic shock according to the SEPSIS-III definition}

This study was performed before the publication of the new sepsis definitions (SEPSIS-III). According to the SEPSIS-III definition, 104 (6.9\%) patients were found to have septic shock. When septic shock was defined according to the SEPSIS-III definition, it was associated with a higher number of organ dysfunctions $(4.4 \pm 11.3$ and $3.7 \pm 1.3$, respectively) and mortality rate $(75.9 \%$ and $70.4 \%$, respectively) in comparison to the 1992 septic shock definitions (SEPSIS-I). However, there are several limitations in applying the new SEPSIS-III definition of septic shock to data from this study. Our database was constructed according to the 1992 consensus criteria of the ACCP/SCCM (SEPSIS-1). Patients who had a mean arterial pressure between 65 and $70 \mathrm{mmHg}$ and were not receiving vasopressors were classified as hypotensive in our database. However, these patients are not classified as having septic shock according to SEPSIS-III 
definitions. Therefore, the actual incidence of septic shock according to SEPSIS-III might be lower.

\section{Strengths and weakness of the study}

This study has some limitations in addition to the lack of data regarding initial appropriate antibiotic treatment. First of all, because of study participation was on a voluntary basis and sampling of ICUs was not a random sample from Turkey, the results might be biased to include more severely ill patients. In Turkey, about $42 \%$ of all ICU beds belong to private hospitals. We observed that only a few ICUs of private hospitals participated in this study. Exclusion of private hospitals could have led to an overestimation of mortality because fewer severely ill patients are looked after in private hospitals. There are 15,513 ICU beds in Turkey, and 1605 patients consented to participate in this study. Therefore, nearly 90\% of Turkey's ICU population did not contribute to the study which is a limitation to generalizability of study results. Second, as mentioned above, it might not have been always possible to differentiate between colonization and infection, especially in terms of VAP cases. These factors may have contributed to the lack of difference in the mortality rates for the CR and CS strains in this study. Furthermore, the doses of antibiotics were not reported, which could be an important variable when the outcomes for patients with sepsis are compared. Third, the educational qualifications of the nurses were not considered in this study. Lastly, this was a point prevalence study, and the prevalence of disease is influenced by both the incidence and duration of disease. Given a constant incidence, an increase in fatality or improvement in disease treatment can decrease the prevalence rate. Despite these limitations, this was a prospective, large epidemiologic study, which provided valuable information about the epidemiology of sepsis in ICUs in Turkey, a middle-income country that is among the countries with a high antibiotic resistance level. To the best of our knowledge, this is the first study to show that the low nurse-to-patient ratio is associated with mortality in infected patients.

\section{Conclusions}

A high prevalence of sepsis and an unacceptably high mortality rate were observed in Turkish ICUs. The carbapenem resistance rate was high in Turkish ICUs, but it was not associated with a higher risk for mortality. Age, APACHE II score at ICU admission, SOFA score on study day, solid organ malignancy, sepsis severity, Candida spp. infection, RRT, and a nurse-to-patient ratio of 1:4 (compared with a nurse-to-patient ratio of 1 : 2) were found to be independent predictors of mortality in infected patients.

\section{Additional files}

Additional file 1: Table S1. Intraclass correlation coefficients (ICCS) with 95\% Cl for the association between predictor variables and mortality, and design effects (Deff) for the entire cohort of infected patients. (DOCX $26 \mathrm{~kb}$ )

Additional file 2: Table S2. Prevalence of infection, sepsis, severe sepsis, and septic shock by hospital and intensive care unit type. (DOCX $100 \mathrm{~kb}$ )

Additional file 3: Table S3. Monitoring techniques and therapies used in patients with severe sepsis and septic shock on study day. (DOCX 76 kb)

Additional file 4: Table S4. Identification of clinical and microbiologic variables associated with 30-day mortality in patients infected with Acinetobacter, Klebsiella, or Pseudomonas spp. using univariate analysis. (DOCX 85 kb)

Additional file 5: Table S5. Identification of clinical and microbiologic variables associated with 30-day mortality using univariate analysis in the entire cohort of infected patients. (DOCX $96 \mathrm{~kb}$ )

\section{Abbreviations}

ACCP/SCCM: American College of Chest Physicians and Society of Critical Care Medicine; APACHE II: Acute physiology and chronic health evaluation II; Cl: Confidence intervals; CR: Carbapenem-resistant; CRF: Case report form; CS: Carbapenem-sensitive; Deff: Design effect; EPIC II: International study of the prevalence and outcomes of infection intensive care units II; ICC: Intraclass correlation coefficient; ICU: Intensive care unit;

MRSA: Methicillin-resistant Staphylococcus aureus; MV: Mechanical ventilation; RRT : Renal replacement therapy; SBP: Systolic blood pressure; SIRS: Systemic inflammatory response syndrome; SOFA: Sequential organ failure assessment

\section{Acknowledgments}

The members of the Sepsis Study Group are as follows: Pınar Özdemir, Hülya Ulusoy, Dilek Memiş, Cavidan Arar, Elif Yılmaz, Melek Çelik, İsmail Cinel, Sibel Temur, Mehmet Akif Yaşar, Hamdiye Tutan Çulha, Canan Balcı, Sultan San, Asena Salbes, Elçin Özkan, Onur Palabıyık, Jale Çelik, Alper Yosunkaya, Faruk Çiçekçi, Işı Özkoçak, İsmail Katı, Hülya Başar, Sema Turan, Süheyla Ünver, Ünase Büyükkoçak, Aynur Akın, Sinan Gürsoy, Demet Tok, Simay Serin, Seda Dursun Kıter, Hakan Doğan, Abdülkadir Oruç, Onur Balaban, Dilara Tüfek, İbrahim Kurt, Murat Bilgi, Verda Tuna, Ayşegül Özkök, Ahmet Şen, Nilay Taş, Hilal Ayoğlu, Berna Kaya Uğur, Sedat Kaya, Mustafa Kahraman, Zahide Doğanay, Gökalp Soykam, Işı Köse, Birgül Yelken, Osman Ekinci, Gönül Ölmez Kavak, Uğur Göktaş, Türkan Togal, Nazım Doğan, Murat Gündüz, Selim Turhanoğlu, Atilla Ramazanoğlu, Füsun Eroğlu, Şaban Yalçın, Hatice Yağmurdur, Atilla Tutak, Ali Aydın Altunkan, Ufuk Kuyrukluyıldız, Gülsüm Oya Hergünsel, Kerem Erkalp, Necati Gökmen, Murat Aksun, Erkan Sayan, Onur Özlü, Yavuz Demiraran, Evren Şentürk, Işın Gençay, Hafize Öksüz, Nihan Yapıcı, Araş Pirat, Tuğhan Utku, Ender Gedik, Orhan Behret, Kadir İdin, Hayrettin Daşkaya, Filiz Banu Ethemoğlu, Ali Alagöz, Seval İzdeş, Mustafa Kemal Bayar, Nermin Kelebek Girgin, Lale Karabıyık, Uğur Koca, Nurcan Çubukçu, Fatma Ülger, Şeyda Efsun Özgünay, Perihan Ergin Özcan, Başar Erdivanlı, Şenay Göksu Tomruk, Abbas Köse, Rafi Doğan, Güldem Turan, Osman Arpaz, Aliye Esmaoğlu, Musa Salmanoğlu, Özgür Canoler, Nedim Çekmen, Canan Kandaz, Gülşen Bulut Kaya, Melis Türker, IIlknur Şeker, Aysu Hayriye Tezcan, Halil İbrahim Uzunlar, Mehmet Akif Yazar, Reyhan Arslantaş, Nalan Adıgüzel, Murat Aksun, Okay Öztürk, Zakir Arslan, Özgür Özmen, Günseli Orhun, Evren Büyükfırat, Oya Çimen Budur, Mehmet Erdem Akçay, Asu Özgültekin, Ertuğrul Kılıç, Makbule Elif Yılmaz, Ömür İlban, Feyza Kargın, Murat Sayın, Feyza Kargın, Resul Altuntaş, Hakan Doğan, Osman Ekinci, Berna Çalışkan, Ayşen Erdoğan, Volkan Alparslan, Murat Tekin.

\section{Funding}

The Turkish Society of Intensive Care helped to construct the study database and collect data.

\section{Availability of data and materials}

The datasets used and analyzed during the current study are available from the corresponding author and with permission of the Turkish Society of Intensive Care.

\section{Authors' contributions}

NB made substantial contributions to the study design, collection, analysis, and interpretation of data, and drafting of the manuscript. HA made 
substantial contributions to study design, collection and analysis of data, and revision of the manuscript. MKA made substantial contributions to study design and collection and analysis of data. VH made substantial contributions to study design, collection and analysis of data, and revision of the manuscript. ÇÇ made substantial contributions to study design and analysis and interpretation of data. NÜ made substantial contributions to study design and revision of the manuscript. FK made substantial contributions to study design and revision of the manuscript. KD made substantial contributions to study design, collection and analysis of data, and revision of the manuscript. CB made substantial contributions to study design and analysis and interpretation of data. The Sepsis Study Group made major contributions to data acquisition. All authors read and approved the final manuscript

\section{Ethics approval and consent to participate}

The Kocaeli University Ethics Committee and Review Board approved the study for all participating centers (Reference number: KOÜKAEK 2016/2). Informed consent was obtained from all participants or their legally acceptable representatives.

\section{Consent for publication}

Not applicable.

\section{Competing interests}

The authors declare that they have no competing interests.

\section{Publisher's Note}

Springer Nature remains neutral with regard to jurisdictional claims in published maps and institutional affiliations.

\section{Author details}

'Department of Anesthesiology, Division of Critical Care, School of Medicine, Kocaeli University, Kocaeli, Turkey. ${ }^{2}$ Department of Infectious Disease, School of Medicine, Uludağ University, Bursa, Turkey. ${ }^{3}$ Department of Anesthesiology, Division of Critical Care, School of Medicine, Marmara University, Istanbul, Turkey. ${ }^{4}$ Department of Anesthesiology, Division of Critical Care, School of Medicine, Dokuz Eylül University, Izmir, Turkey. ${ }^{5}$ Department of Public Health, School of Medicine, Kocaeli University, Kocaeli, Turkey. ${ }^{6}$ Department of Anesthesiology, Division of Critical Care, School of Medicine, Uludağ University, Bursa, Turkey. ${ }^{7}$ Department of Anesthesiology, Division of Critical Care, School of Medicine, Ege University, İzmir, Turkey. ${ }^{8}$ Department of Biostatistics and Medical informatics, School of Medicine, Kocaeli, Turkey. ${ }^{9}$ Department of Anesthesiology, Division of Critical Care, School of Medicine, Ankara University, Ankara, Turkey.

\section{Received: 23 October 2017 Accepted: 12 March 2018}

\section{Published online: 16 April 2018}

\section{References}

1. Fleischmann C, Scherag A, Adhikari NK, Hartog CS, Tsaganos T, Schlattmann $P$, et al. Assessment of global incidence and mortality of hospital-treated sepsis. Current estimates and limitation. Am J Respir Crit Care Med. 2016;193:259-72.

2. Kumar G, Kumar N, Taneja A, Kaleekal T, Tarima S, McGinley E, et al. Milwaukee Initiative in Critical Care Outcomes Research Group of Investigators. Nationwide trends of severe sepsis in the 21st century (2000-2007). Chest. 2011;140:1223-31.

3. SepNet Critical Care Trials Group. Incidence of severe sepsis and septic shock in German intensive care units: the prospective, multicentre INSEP study. Intensive Care Med. 2016:42:1980-9.

4. Dombrovskiy VY, Martin AA, Sunderram J, Paz HL. Rapid increase in hospitalization and mortality rates for severe sepsis in the United States: a trend analysis from 1993 to 2003. Crit Care Med. 2007;35:1244-50.

5. Whittaker SA, Fuchs BD, Gaieski DF, Christie JD, Goyal M, Meyer NJ, et al. Epidemiology and outcomes in patients with severe sepsis admitted to the hospital wards. J Cric Care. 2015;30:78-84

6. Degoricija V, Sharma M, Legac A, Gradiser M, Sefer S, Vucicevic Z. Survival analysis of 314 episodes of sepsis in medical intensive care unit in university hospital: impact of intensive care unit performance and antimicrobial therapy. Croat Med J. 2006:47:385-97.
7. Walkey AJ, Lagu T, Lişndenauer PK. Trends in infection and sepsis sources in the United States. A population-based study. Ann Am Thorac Soc. 2015;12:216-20.

8. Zimmerman JE, Kramer AA, Knaus WA. Changes in hospital mortality for United States intensive care unit admissions from 1988 to 2012. Crit Care. 2013;17:R81

9. Miller RR, Dong L, Nelson NC, Brown SM, Kuttler KG, Probst DR, et al. Multicenter implementation of a severe sepsis and septic shock treatment bundle. Am J Respir Crit Care Med. 2013;188:77-82.

10. Martin GS, Mannino DM, Eaton S, Moss M. The epidemiology of sepsis in the United States from 1979 through 2000. N Engl J Med. 2003;348:1546-54.

11. Kaukonen KM, Bailey M, Suzuki S, Pilcher D, Bellomo R. Mortality related to severe sepsis and septic shock among critically ill patients in Australia and New Zealand, 2000-2012. JAMA. 2014;311:1308-16.

12. Cheng B, Xi EG, Yao S, Wu X, Guo Q, Gu M, et al. Epidemiology of severe sepsis in critically ill surgical patients in ten university hospitals in China. Crit Care Med. 2007;35:2538-46.

13. Zhou J, Qian C, Zhao M, Yu X, Kang Y, Ma X, et al. Epidemiology and outcome of severe sepsis and septic shock in intensive care units in mainland China. PLoS One. 2014:9:e107181.

14. Phua J, Koh Y, Du B, Tang YQ, Divatia JV, Tan CC, et al. Management of severe sepsis in patients admitted to Asian intensive care units: prospective cohort study. BMJ. 2011;342:d3245.

15. Cecchini M. Antimicrobial resistance. OECD. 2017. Available from https://www. oecd.org/health/health-systems/AMR-Policy-Insights-November2016.pdf. Accessed 4 Apr 2018.

16. Daikos GL, Petrikkos P, Psichogiou M, Kosmidis C, Vryonis E, Skoutelis A, et al. Prospective observational study of the impact of VIM-1 metallo-betalactamase on the outcome of patients with Klebsiella pneumoniae bloodstream infections. Antimicrob Agents Chemother. 2009;53:1868-73.

17. Playford EG, Craig JC, Iredell JR. Carbapenem-resistant Acinetobacter baumanii in intensive care unit patients:risk factors for acquisition, infection and their consequences. J Hosp Infect. 2007:65:204-11.

18. Falagas ME, Rafailidis PI, Kofteridis D, Virtzili S, Chelvatzoglou FC, Papaioannou V, et al. Risk factors of carbapenem-resistant Klebsiella pneumoniae infections: a matched case control study. J Antimicrob Chemother. 2007:60:1124-30.

19. Gaviria D, Bixler D, Thomas CA, Ibrahim SM, Kallen A, Limbago B, et al. Carbapenem-resistant Klebsiella pneumoniae associated with a longterm-care facility-West Virginia, 2009- 2011. MMWR Morb Mortal Wkly Rep. 2011;60:1418-20.

20. Bone RC, Balk RA, Cerra FB, Dellinger RP, Fein AM, Knaus WA, et al. Definition for sepsis and organ failure and guidelines for the use of innovative therapies in sepsis. The ACCP/SCCM Consensus Conference Committee. American College of Chest Physicians/Society of Critical Care Medicine. Chest. 1992;101:1644-55.

21. Calandra T, Cohen J, International Sepsis Forum Definition of Infection in the ICU Consensus Conference. International sepsis forum definition of infection in the intensive care unit. Crit Care Med. 2005:33:1538-48.

22. Seymour CW, Liu VX, Iwashyna TJ, Brunkhorst FM, Rea TD, Scherag A, et al. Assessment of clinical criteria for sepsis: for the Third International Consensus Definitions for Sepsis and Septic Shock (Sepsis-3). JAMA. 2016;315:762-74.

23. Peugh JL. A practical guide to multilevel modeling. J Sch Psychol. 2010; 48(1):85-112.

24. Esen S, Leblebicioğlu H. Prevalence of nosocomial infections at intensive care units in Turkey: a multicentre 1-day point prevalence study. Scand J infect Dis. 2004;36:144-8.

25. Vincent JL, Rello J, Marshall J, Silva E, Anzueto A, Martin CD, et al. International study of the prevalence and outcomes of infection in intensive care units. JAMA. 2009:302:2323-9.

26. OECD. OECD Reviews of Health Care Quality: Turkey 2014: Raising standards. Paris: OECD Publishing; 2014.

27. Bal MD. Nursing manpower planning approaches in hospital. J Health Nurs Manag. 2014;3:148-54

28. McGhan M, Kucharski G, Coyer F. Nurse staffing levels and the incidence of mortality and morbidity in the adult intensive care unit: a literature review. Aust Crit Care. 2012;25:64-77

29. Numata Y, Schulzer M, van der Wal R, Globerman J, Semeniuk P, Balka E, et al. Nurse staffing levels and hospital mortality in critical care settings literatüre review and meta-analysis. J Adv Nurs. 2006:55:435-48.

30. Neuraz A, Guérin C, Payet C, Polazzi S, Aubrun F, Dailler F, et al. Patient mortality is associated with staff resources and workload in the ICU: a multicenter observational study. Crit Care Med. 2015;43:1587-94. 
31. Cho SH, Hwang JH, Kim J. Nurse staffing and patient mortality in intensive care units. Nurs Res. 2008;57:322-30.

32. Kübler A, Adamik B, Ciszewicz-Adamiczka B, Ostrowska E. Severe sepsis in intensive care units in Poland-a point prevalence study in 2012 and 2013. Anaesthesiol Intensive Ther. 2015;47:315-9.

33. Machado FR, Brazil CAB, Bozza F, Angus DC, Ferreira EM, Carrara F, et al. Epidemiology of sepsis in Brazilian ICUs: a nationwide stratified sample. Intensive Care Med. 2015;3:A642.

34. Mayr FB, Yende S, Angus DC. Epidemiology of severe sepsis. Virulence. 2014;5:4-11.

35. Angus DC, Sirio CA, Clermont G, Bion J. International comparisons of critical care outcome and resource consumption. Crit Care Clin. 1997;13:389-407.

36. Levy MM, Rhodes A, Phillips GS, Townsend SR, Schorr CA, Beale R, et al. Surviving Sepsis Campaign: association between performance metrics and outcomes in a 7.5-year study. Crit Care Med. 2015:43:3-12.

37. Rhodes A, Phillips G, Beale R, Cecconi M, Chiche JD, De Backer D, et al. The Surviving Sepsis Campaign bundles and outcome: results from the International Multicentre Prevalence Study on Sepsis (the IMPreSS study). Intensive Care Med. 2015;41:1620-8.

38. Tanriöver MD, Guven S, Sen D, Unal S, Uzun O. Epidemiology and outcome of sepsis in a tertiary-care hospital in a developing country. Epidemiol Infect. 2006;134:315-22.

39. Tufan ZK, Eser FC, Vudali E, Batirel A, Kayaaslan B, Bastug AT, et al. The knowledge of the physicians about sepsis bundles is suboptimal: a multicenter survey. J Clin Diagn Res. 2015;9:0C13-6.

40. Danai PA, Sinha S, Moss M, Haber MJ, Martin GS. Seasonal variation in the epidemiology of sepsis. Crit Care Med. 2007;35:410-5.

41. Todi S, Chatterjee S, Bhattacharyya M. Epidemiology of severe sepsis in India. Crit Care. 2007;11(Suppl 2):P65.

42. Siddiqui S. Not "surviving sepsis" in the developing countries. J Coll Physicians Surg Pak. 2006;16:800-1.

43. Frikha N, Mebazaa M, Mnif L, El Euch N, Abassi M, Ben Ammar MS. Septic shock in a Tunisian intensive care unit: mortality and predictive factors. 100 cases. Tunis Med. 2005;83:320-5.

44. Maechler F, Pena Diaz LA, Schröder C, Geffers C, Behnke M, Gastmeier P. Infection. Prevalence of carbapenem-resistant organisms and other Gramnegative MDRO in German ICUs: first results from the national nosocomial infection surveillance system (KISS). Infection. 2015;43:163-8.

45. Sader HS, Farrell DJ, Flamm RK, Jones RN. Antimicrobial susceptibility of Gram-negative organisms isolated from patients hospitalized in intensive care units in United States and European hospitals (2009-2011). Diagn Microbiol Infect Dis. 2014;78:443-8.

46. Ben-David D, Kordevani R, Keller N, Tal I, Marzel A, Gal-Mor O, et al. Outcome of carbapenem resistant Klebsiella pneumoniae bloodstream infections. Clin Microbiol Infect. 2012;18:54-60

47. Matthaiou DK, Christodoulopoulou T, Dimopoulus G. How to treat fungal infections in ICU patients. BMC Infect Dis. 2015;15:205.

48. Paiva JA, Tabah A, Mikstacki A, de Carvalho FB, Koulenti D, Ruckly S, et al. Characteristics and risk factors for 28-day mortality of hospital acquired fungemias in ICUs: data from the EUROBACT study. Crit Care. 2016;20:53.

49. Bassetti M, Righi E, Ansaldi F, Merelli M, Trucchi C, et al. A multicenter study of septic shock due to candidemia: outcomes and predictors of mortality. Intensive Care Med. 2014;40(6):839-45.

\section{Submit your next manuscript to BioMed Central and we will help you at every step:}

- We accept pre-submission inquiries

- Our selector tool helps you to find the most relevant journal

- We provide round the clock customer support

- Convenient online submission

- Thorough peer review

- Inclusion in PubMed and all major indexing services

- Maximum visibility for your research

Submit your manuscript at www.biomedcentral.com/submit

) Biomed Central 